\title{
Successful endoscopic treatment (clipping) of esophageal perforation during balloon dilatation in a patient with achalasia
}

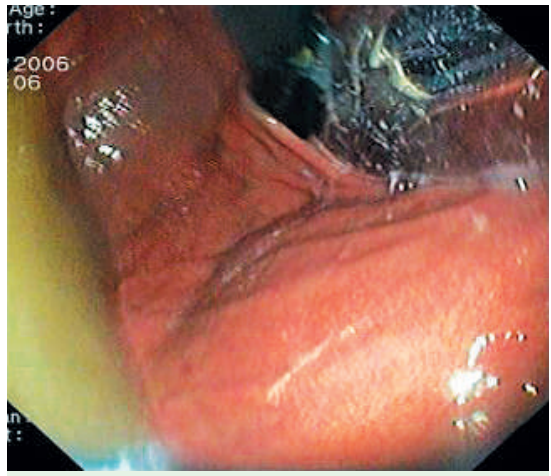

Fig. 1 Balloon before full inflation from a retroflexed view.

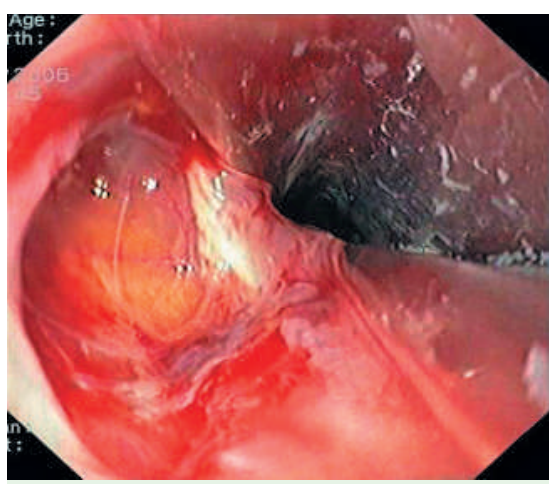

Fig. 3 Perforation of the esophagus (left) and balloon (right).

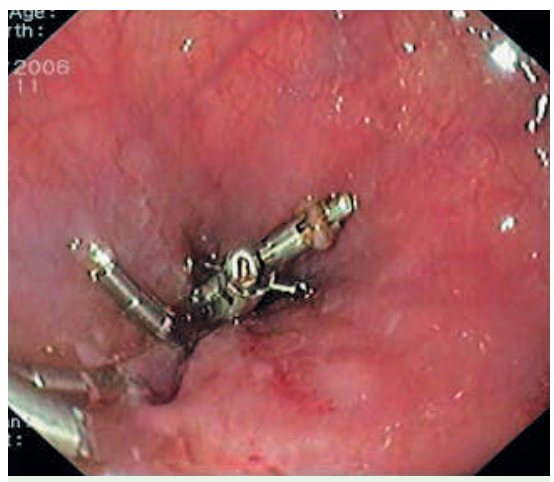

Fig. 5 Final endoscopic view after clipping.

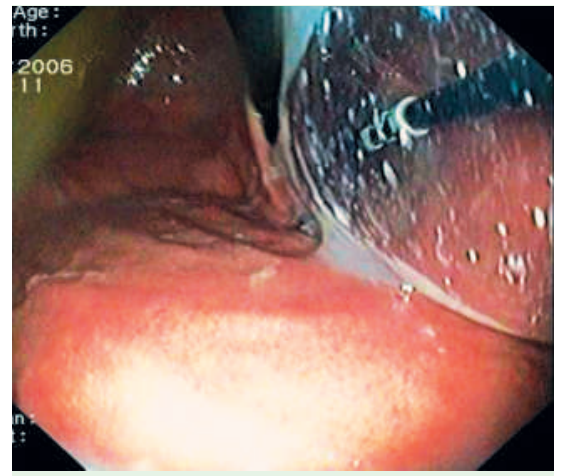

Fig. 2 Inflated Rigiflex balloon under endoscopic control from a retroflexed view.

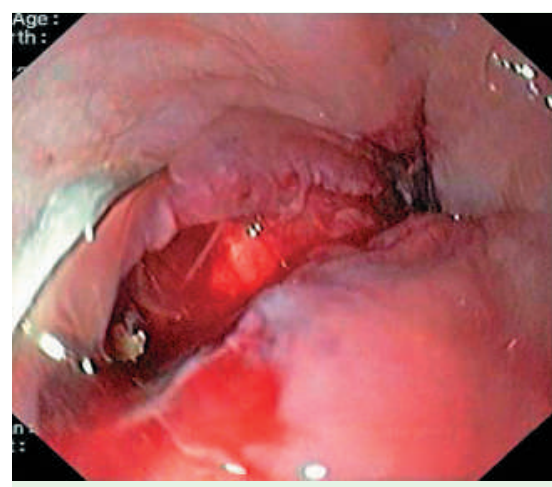

Fig. 4 Transmural perforation of the esophageal wall.

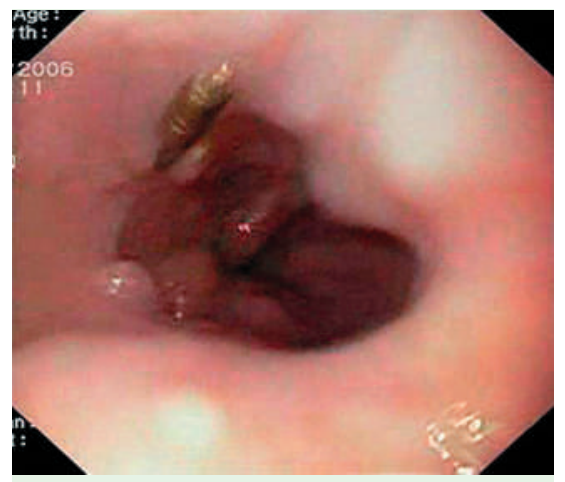

Fig. 6 Endoscopic view of healed perforation (with one clip remaining) 3 months after the perforation.
We describe the case of a 63-year-old woman with a 20-year history of intermittent dysphagia and regurgitation worsening over the past 6 years. The patient underwent balloon dilatation as the first treatment of her disease. A Rigiflex balloon dilator (Boston Scientific, Boston, MA, USA) with a diameter of $30 \mathrm{~mm}$ was positioned over a guide wire at the gastroesophageal junction under endoscopic control. An endoscope was introduced to the stomach next to the balloon and then retroflexed to control the procedure ( $\bullet$ Fig. 1 and $\bullet 2$ ). We gradually inflated the balloon to 8 psi within 30 seconds and the pressure was maintained for 1 minute.

During the procedure, the esophageal wall was ruptured. The rupture $(3.5 \mathrm{~cm}$ long) involved the gastrointestinal junction and distal esophagus ( Fig. 3 and - 4). Immediately after discovering the complication, we started endoscopic clipping. We sealed the rupture with nine clips ( Fig. 5). Then we placed a nasogastric tube through a guide wire. Not surprisingly, subcutaneous emphysema developed, but spontaneously regressed within a few days. The day after perforation, the patient had a slight elevation of C-reactive protein, a borderline white cell count, and pleural effusion. Eleven days later, radiography and endoscopy showed no signs of perforation. The patient was discharged on day 11 to receive home care. Endoscopic follow-up 12 weeks later showed a healed perforation site with one clip remaining on site (the "high-resolution" clip placed as the first one, Fig. 6). The cardia is nonspastic, open, and there is only mild reflux esophagitis, which has been treated with a proton pump inhibitor. The patient is currently asymptomatic, free of dysphagia and regurgitation.

In summary, we have shown that endoscopic treatment of a large esophageal perforation is a possible and effective alternative to standard surgical treatment.

Endoscopy_UCTN_Code_CPL_1AH_2AF 
J. Martinek ${ }^{1,4}$, S. Kovacova ${ }^{1}$, V. Nosek ${ }^{3}$, T. Verner ${ }^{2}$, M. Vasicek ${ }^{1}$, J. Spicak ${ }^{4}$

1 Department of Gastroenterology, Claudian Hospital, V. Klementa 147, Mladá Boleslav, Czech Republic

2 Department of Surgery, Claudian Hospital, V. Klementa 147, Mladá Boleslav, Czech Republic

3 Department of Gastroenterology, Hospital Jablonec nad Nisou, Nemocniční 15, Jablonec nad Nisou, Czech Republic

4 IKEM (Institute for Clinical and Experimental Medicine), Vídeňská 1958, 140 21 Praha 4, Czech Republic
Bibliography

DOI 10.1055/s-2007-995495

Endoscopy 2008; 40: E61 -E62

(C) Georg Thieme Verlag KG Stuttgart · New York . ISSN 0013-726X
Corresponding author

J. Martínek, MD, PhD

Department of Hepatogastroenterology IKEM

Videnska 1958

14021 Praha 4

Czech Republic

jan.martinek@medicon.cz 